\title{
Efficacy of an Arabic articulatory errors remediation software program in patients with velopharyngeal valve dysfunction: a quasi-experimental study
}

Reham Mohamed Elmaghraby ${ }^{1}$, Engy Samy Elhakeem², Alaa Mamdouh abdelhamed Radwan ${ }^{2 *}$ (D) and Rami Nabil Abdelkader Elsalakawy ${ }^{3}$

\begin{abstract}
Background: Velopharyngeal dysfunction causes abnormal speech due to altered nasal resonance during the production of oral speech sounds. The development of computer-based speech therapy has been growing to make use of computer technology in providing an organized effective source for speech therapy and feedback. The development of a remediation software program that is specific for patients with velopharyngeal dysfunction in the Arabic language and testing its efficacy on patients' speech was the aim of this study.

Results: The study showed significant improvement in speech parameters after intervention with $p$ value less than 0.05 for nasometer values and parameters of auditory perceptual assessment. The study proved a significant relation between nasometer values and auditory perceptual assessment.

Conclusion: The designed software program proved to be a good therapeutic tool in improving speech in patients with velopharyngeal dysfunction. The application of the program on a larger number of patients and in comparison with traditional methods of speech therapy and biofeedback is recommended.
\end{abstract}

Trial registration: The study was retrospectively registered at www.clinicaltrials.gov NCT04392817

Keywords: Velopharyngeal dysfunction, Hypernasality, Biofeedback, Articulation

\section{Background}

Normal speech production depends upon coordination between the four important physiological processes which are respiration, phonation, articulation, and resonance [1]. Velopharyngeal valve plays an important role in speech production through the regulation of acoustic energy to the nasal pathway when producing nasal speech sounds and to the oral pathway when producing oral speech sound $[2,3]$.

\footnotetext{
*Correspondence: A_abdelhamed14@alexmed.edu.com

¿Unit of Phoniatrics, Otorhinolaryngology Department, Faculty of Medicine, Alexandria University, Alexandria, Egypt

Full list of author information is available at the end of the article
}

Inadequate function of the velopharyngeal valve leads to inadequate closure of the valve, which affects speech production. This is referred to as velopharyngeal dysfunction. This may be due to either structural defects, neurological affection, myopathic affection, or functional (with no apparent cause) [4].

Speech affection can be classified into (i) passive errors which occur due to a gap on velopharyngeal closure in the form of: hypernasality, weak imprecise consonants, and short utterance length; and (ii) compensatory articulatory errors when the articulatory movements for different phonemes change due to dysfunction. These errors include glottal stops and fricatives, pharyngealization, velar plosives, and nasal fricatives $[5,6]$.

\section{Springer Open}

๑ The Author(s). 2020 Open Access This article is licensed under a Creative Commons Attribution 4.0 International License which permits use, sharing, adaptation, distribution and reproduction in any medium or format, as long as you give appropriate credit to the original author(s) and the source, provide a link to the Creative Commons licence, and indicate if changes were made. The images or other third party material in this article are included in the article's Creative Commons licence, unless indicated otherwise in a credit line to the material. If material is not included in the article's Creative Commons licence and your intended use is not permitted by statutory regulation or exceeds the permitted use, you will need to obtain permission directly from the copyright holder. To view a copy of this licence, visit http://creativecommons.org/licenses/by/4.0/. 
Assessment of VPD includes (a) adequate history taking to search for possible causes, (b) physical examination of the vocal tract, (c) auditory perceptual assessment of patient's speech (d) clinical diagnostic tests for nasal air emission and nasal tone, (f) examination and documentation of velopharyngeal valve closure by nasopharyngoscope, and (g) instrumental assessment by nasometer and aerodynamic measures [7].

Management of VPD differs according to the cause, size of the gap, and the function. The main lines include surgical, prosthetic, and speech therapy [3]. Determining the proper surgery depends on the size of the gap and the main contributors to closure (soft palate or lateral pharyngeal walls) [3]. Prosthesis are used in cases which are contraindicated or delayed surgery. Palatal lift is suitable for adequate length but immobile soft palate, while speech bulb for inadequate length soft palate [8-10].

Speech therapy cannot correct structural defects but is important for correcting functional (speech errors). Kummer A.W (2008) stated that indications of speech therapy in cases of VPD include compensatory articulation productions due to VPI, hypernasality which is phoneme specific, hypernasality due to apraxia of speech, and persistent hypernasality after surgical correction of velopharyngeal insufficiency [11]. Biofeedback methods can be used with speech therapy including simple methods as straw and air paddle or more advanced methods as nasopharyngoscopy and nasometer games $[12,13]$.

Designing software programs has been emerging as an advanced tool for speech and language therapy for speech sound disorders, dyslexia, prosody, and aphasia. These programs were designed in many languages as English, Romanian, Turkish, and other languages [14].

There is a lack of software programs in the Arabic language for speech therapy in VPD. So the aim of this study was to design a software program in Arabic language for correcting speech errors in VPD and to test if it was effective for Arabic-speaking patients with VPD.

\section{Methods}

\section{Aim of the work}

To design a remediation software program in Arabic language specific for articulatory errors in patients with velopharyngeal dysfunction and to test its efficacy on nasometer values, articulation, and auditory perceptual assessment of patient's speech.

\section{Designing the program}

The software program was first designed according to the phonetic approach in the following steps: (I) discriminating incorrect production, (II) awareness of the correct production, (III) production of the correct phoneme in initial, middle, final position in words and sentences. This is done through (a) animated graphs of the vocal tract and (b) auditory feedback. The interface of the program includes seven main menus: patient data, glottalization, distorted $\mathrm{R}$ sound, nasalized phoneme, palatal dorsal production, pharyngeal fricatives, pharyngeal plosives, backing, nasalized vowels, and test yourself. The patient data menu includes personal data of the patients, their pre therapy evaluation, and follow-up evaluation. The "test your self" menu includes simple sentences and questions related to these sentences to be answered by the patient. The patient recorded his answer and listened back to evaluate if the errors were corrected or not. The remaining menus includes auditory discrimination menu, awareness menu, and production menu.

\section{The subjects and methods}

The study was designed as a quasi-experimental comparing pre- and post-intervention outcomes. The ethics committee of the Faculty of Medicine approved the study (no. 0105440). The study was retrospectively registered at www.clinicaltrials.gov NCT04392817. The sample size included 40 patients chosen randomly from patients attending the Unit of Phoniatrics, Otorhinolaryngology Department, Alexandria University. Inclusion criteria: age of 5 years and above with articulation errors due to VPD, normal hearing, and vision. Exclusion criteria: unrepaired cleft palate or large fistula, patients with brain damage, and intellectual disability.

The patients were diagnosed through complete history taking, physical examination, clinical diagnostic tests, and instruments: nasopharyngolaryngoscopy to assess velopharyngeal valve closure during speech tasks: sentences loaded with oral and nasal phonemes, and automatic speech counting from 1 to 10 . This procedure determines the cause of dysfunction whether structural deficiency or velopharyngeal mislearning.

Nasometer II model 6450 was used to assess nasalance score for vowels $/ \mathrm{a} /, / \mathrm{i} /, / \mathrm{u} /$, consonants $/ \mathrm{b} /, / \mathrm{t} /, / \mathrm{k} /$, nasal sentences, and oral sentences. Normative data for nasometer values were considered according to Kotby et al. [7] and Abou-Elsaad et al. [15]: /a/ $5 \pm 4 \%$, /i/ $15 \pm$ $7 \%, / \mathrm{u} / 8 \pm 5 \%, / \mathrm{b} / 14 \pm 8 \%, / \mathrm{t} / 15 \pm 8 \%, / \mathrm{k} / 11 \pm 9 \%$, nasal sentence $47 \%$, and oral sentence $10 \%$.

Articulation errors were diagnosed by the Arabic articulation test by Kotby et al. [16] which is descriptive for each phoneme in the Arabic language in the initial, middle, and final positions. Phonemes included are $(/ \Theta /, / \mathrm{s} /, / \mathrm{z} /, / \breve{s} /, / \mathrm{f} /, / \mathrm{h} /, / \mathrm{P} /, / \mathrm{x} /, / \mathrm{J} /, / \mathrm{h} /, / \mathrm{b} /$, 
$/ \mathrm{t} /, / \mathrm{d} /, / \mathrm{d}^{-} /, / \mathrm{t}^{-} /, / \mathrm{k} /, / \mathrm{g} /, / \mathrm{s} /, / \mathrm{\gamma} /, / 1 /, / \mathrm{r} /, / \mathrm{m} /, / \mathrm{n} /, / \mathrm{j} /$, $/ \mathrm{w} /$ ). The errors were labeled as the following: glottal stops, pharyngeal fricatives, backing, distorted $/ \mathrm{r} /$ sound, substitution of oral plosives $/ \mathrm{b} /, / \mathrm{t} /$, and $/ \mathrm{k} / \mathrm{with}$ nasal sounds (nasalized phonemes) [17, 12].

The speech of the patients was evaluated by auditory perceptual assessment and grading of the degree of nasality, glottalization, pharyngealization, consonant imprecision, and overall intelligibility through a 5grade scale beginning from 0 (normal) to 4 (severe). Evaluation of automatic speech and specified sentences containing for each phoneme in initial, middle, and final positions [18].

The program was applied in the form of individual sessions in a duration ranging from minimum 1 month (in cases with phoneme specific hypernasality, velopharyngeal mislearning, who responded in a short time and did not need further sessions) to a maximum 6 months, about 2 sessions per week, 30 min each, according to the number of errors in each case. It was applied in the outpatient clinic.

The sessions start by (1) auditory discrimination of the articulatory error: the patient listened to a chosen word and recorded his production to listen back to his production and the correct word. (2) Awareness of the correct production. (3) Trial producing the correct phoneme in syllables, initial, middle, and final positions. (4) Trying to produce sentences and stories loaded with the phoneme. The patient was wearing headphones and using a recording icon on the program. This provides auditory feedback to the patient. (see the Appendix for screenshots of the program). We used visual and auditory stimulus. The patients were required to do some home exercises to increase practice. A CD containing some examples from the program was given to the patients who ha computers at home.

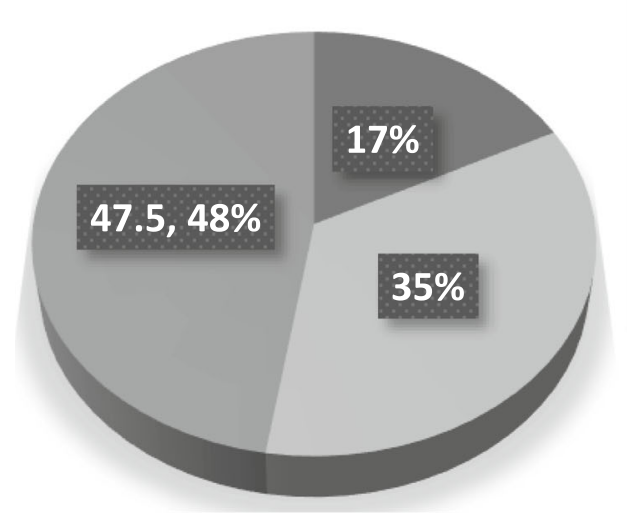

After finishing the therapy, the patients were reevaluated by nasometer II for nasalance scores, Arabic articulation test to assess the articulatory errors, if corrected or not, auditory perceptual assessment as previously mentioned. The data were blindly collected and analyzed.

\section{Statistical analysis}

Statistical analysis was carried out using SPSS statistics software version 23. Quantitative data were tested for normality using the Kolmogorov-Smirnov test. The variables which were normally distributed were described by mean \pm SD. The variables which were not normally distributed were described by median (min-max). Qualitative data were expressed by numbers and percentages. The results were calculated at a level of significance of $5 \%$ or less.

\section{Results}

They were $55 \%$ males and $45 \%$ females, with mean age of $9.22 \pm 3.02$ years. Figure 1 shows that by nasopharyngoscopy, $47.5 \%$ had compensatory errors with repaired velopharyngeal insufficiency VPI with no gap on speech production (corrected either by primary repaired cleft palate, palatoplasty, or were secondary repaired by superiorly based pharyngeal flap). Thirtyfive percent were found to have errors due to velopharyngeal mislearning, referring to functional or habitual VPD and $17.5 \%$ had compensatory errors due to unrepaired VPI with a gap on speech production (those include 5 patients who had primary repair of overt cleft palate and residual post-operative velopharyngeal insufficiency and 2 patients with deep pharynx).

Table 1 shows distribution of different articulatory errors in each group and their frequency is shown. The distribution of articulatory errors was similar in both repaired and unrepaired VPI groups. The
- Unrepaired VPI with compenastiry errors

- Velopharyngeal misleaming

Repaired VPI with compenastiry errors

Fig. 1 Distribution of the sample according to the etiology 
Table 1: Frequency of each articulatory error in each group

\begin{tabular}{|c|c|c|c|c|c|c|}
\hline & \multicolumn{2}{|c|}{ Repaired VPI } & \multicolumn{2}{|c|}{$\begin{array}{l}\text { Velopharyngeal } \\
\text { mislearning }\end{array}$} & \multicolumn{2}{|c|}{ Unrepaired VPI } \\
\hline & No. & $\%$ & No. & $\%$ & No. & $\%$ \\
\hline Substitution errors (Nasalized phonemes) & 20 & 35 & 10 & 34 & 11 & 55 \\
\hline Pharyngeal fricatives & 18 & 31.5 & 8 & 27.5 & 5 & 25 \\
\hline Glottal stops & 10 & 17.5 & 4 & 14 & 2 & 10 \\
\hline Backing & 5 & 9 & 2 & 7 & 0 & 0 \\
\hline Lateral fricatives & 2 & 3.5 & 4 & 14 & 1 & 5 \\
\hline Distorted /r/ sound & 2 & 3.5 & 1 & 3.4 & 1 & 5 \\
\hline Total no. of defects & 57 & 100 & 29 & 100 & 20 & 100 \\
\hline
\end{tabular}

substitution errors (nasalized phonemes: oral sounds $/ \mathrm{b} /, / \mathrm{t} /$, and $/ \mathrm{k} /$ replaced by nasal sounds) [12, 17], were the most common followed by pharyngeal fricatives then glottal stops.

Figures 2, 3, 4, 5, and 6 show post-intervention correction of articulatory errors regarding the results of the Arabic articulation test. These are described as percentages: completely corrected if all positions were pronounced correctly, partially corrected if one or two positions were pronounced correctly and not corrected if no position was correct.

Table 2 shows that there was statistically significant improvement between the medians of auditory perceptual assessment grades before and after therapy for degree of nasality, degree of glottalization, degree of pharyngealization, consonant imprecision, and overall intelligibility.
The subjective scores of auditory perceptual assessment of speech post-therapy were rated by 2 phoniatricians for 32 cases who complied till the end of the treatment program. While eight cases did not come for assessment by the second assessor. Table 3 shows that the agreement between the two raters ranged from good agreement for degree of nasality and glottalization, to moderate agreement for pharyngealization, consonant imprecision, and overall intelligibility.

Table 4 shows that there was no significant difference in the post-intervention degree of auditory perceptual assessment between patients with repaired and patients with unrepaired velopharyngeal insufficiency using Mann-Whitney test.

There was a statistically significant improvement in mean of post-intervention nasometer values when compared to pre-therapy values as shown in Table 5 .

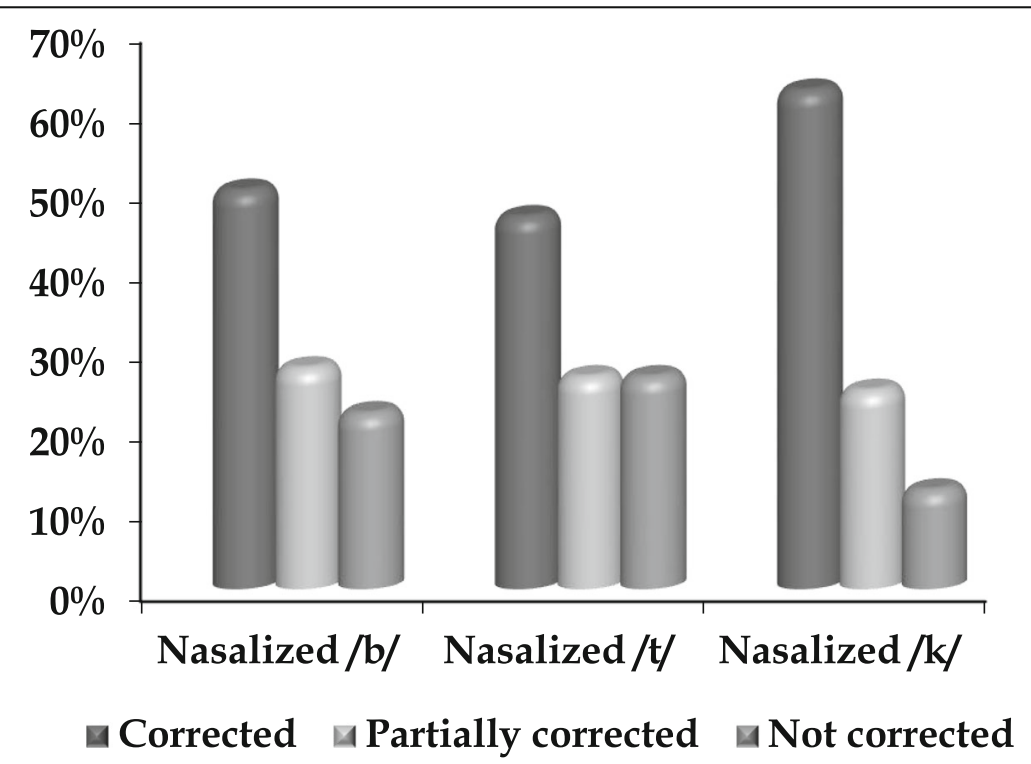

Fig. 2 Distribution of the studied cases after intervention $(n=40)$ 


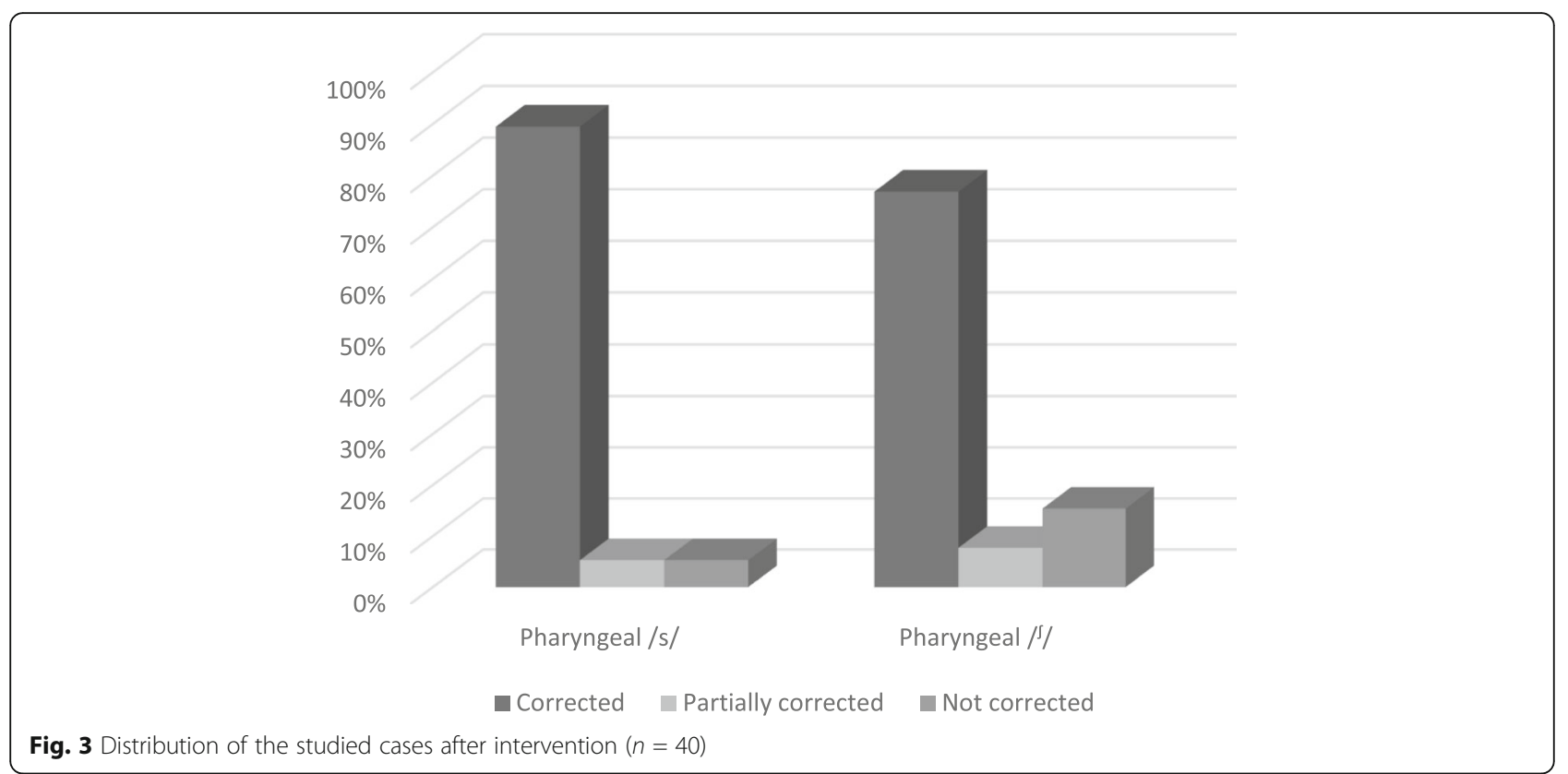

Studying relation of age to nasometer values pre- and post-therapy, there was a positive correlation between age and nasometer value of oral sentence only pre- and post-therapy but not for other nasometer values as shown in Table 6. That denotes that age was not a prognostic factor for improvement in nasality score by nasometer values except for oral sentence.

Comparing the group with compensatory errors following repaired VPI and compensatory errors with unrepaired VPI according to nasometer values post-therapy showed no statistically significant difference between the two groups as shown in Table 7.
Correlations between the degree of severity of auditory perceptual assessment (degree of nasality, glottalization, pharyngealization, consonant imprecision, overall intelligibility) before intervention and degree of improvement after intervention using Pearson coefficient showed moderately positive correlation for the degree of open nasality and glottalization. Correlation for the degree of pharyngeal fricatives was weakly positive. Correlation for degree of consonant imprecision and overall intelligibility was strongly positive as shown in Table 8.

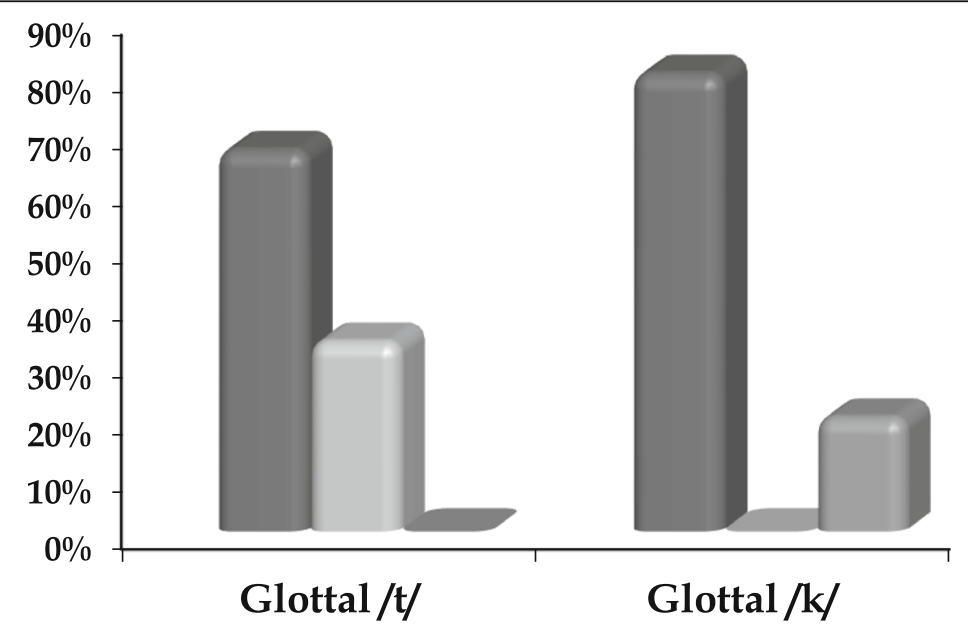

国Corrected $\mathbf{a}$ Partially corrected $\mathbf{a}$ Not corrected

Fig. 4 Distribution of the studied cases after intervention $(n=40)$ 


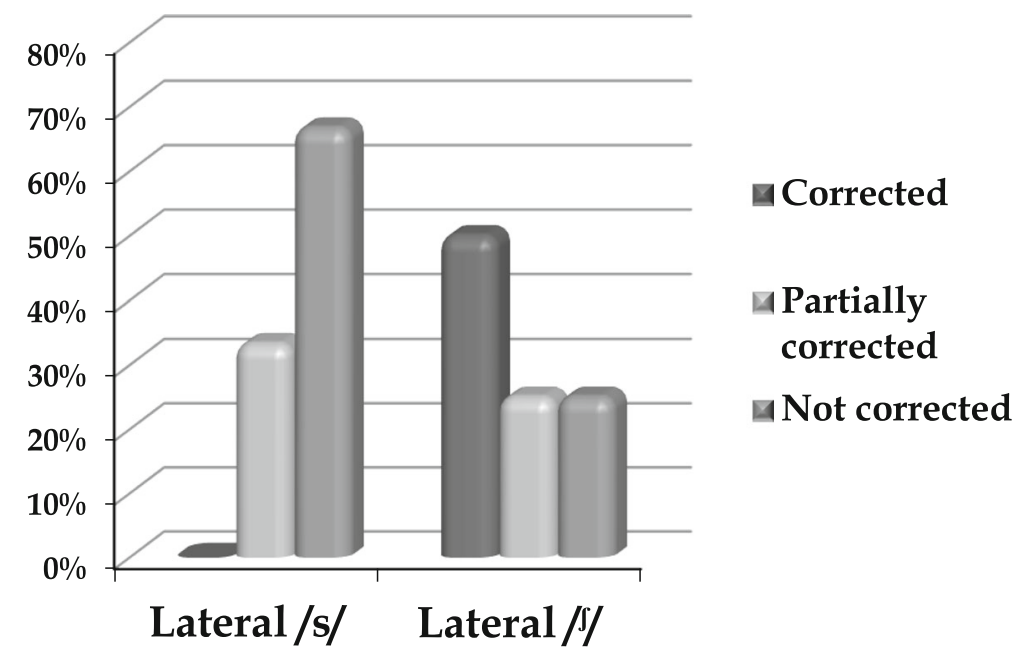

Fig. 5 Distribution of lateral fricatives errors after intervention

There was a moderately positive correlation between the degree of nasality and nasometer values for $/ \mathrm{i} /, / \mathrm{u} /$, and oral sentence before the intervention and there was a weak positive correlation between the degree of nasality and nasometer values for $/ \mathrm{k} /$ and oral sentence after intervention as shown in Table 9.

\section{Discussion}

Patients with VPD usually have passive and/or active speech errors that necessitate speech therapy. Designing and testing the efficacy of a software program for speech therapy in Arabic-speaking patients with VPD were the aims of this study.
Regarding the age factor, the patients' mean age was 9.02 years and the standard deviation of 3.22 years. There were 4 cases aged 14-15 years with 3 of them showed good response, needed less number of sessions, and they showed also low compliance to therapy.

There was a significant relationship between age and some nasometer values including $/ \mathrm{i} /, / \mathrm{u} /$, and oral sentence before therapy. This denotes that nasometer values were higher with older ages rather than lower age. This finding could be attributed to some anatomical changes that occur with aging suggested by Siegel-Sadewitz and Shprintzen which include involution of adenoid, decrease in lateral pharyngeal walls movement and change in the closure pattern [19].

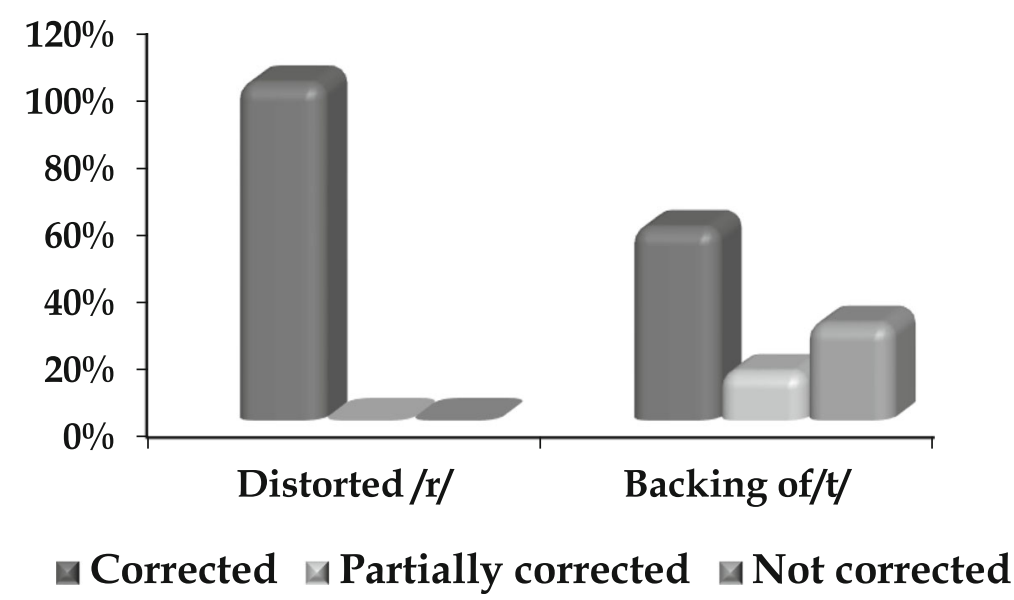

Fig. 6 Distribution of the studied cases after intervention $(n=40)$ 
Table 2 Comparison between medians of degree of auditory perceptual assessment of speech before and after intervention

\begin{tabular}{|c|c|c|c|}
\hline & $\begin{array}{l}\text { Before intervention } \\
(n=40)\end{array}$ & After intervention $(n=40)$ & $\begin{array}{l}\text { Test of significance } \\
(p)\end{array}$ \\
\hline \multicolumn{4}{|l|}{ Degree of nasality } \\
\hline Median (min-max) & $1.5(0-3)$ & $1(0-2)$ & $\left(z=-4.2, p<.0001^{* *}\right)$ \\
\hline \multicolumn{4}{|l|}{ Glottal } \\
\hline Median (min-max) & $0(0-3)$ & $0(0-3)$ & $\left(z=\left(z=-2.8, p<.004^{*}\right)\right.$ \\
\hline \multicolumn{4}{|l|}{ Pharyngeal fricative } \\
\hline Median (min-max) & $1.5(0-3)$ & $0(0-3)$ & $\left(z=-4.1, p<.0001^{* *}\right)$ \\
\hline \multicolumn{4}{|l|}{ Consonant imprecision } \\
\hline Median (min-max) & $1(0-2)$ & $0(0-2)$ & $(z=-4.03, p<.0001 * *)$ \\
\hline \multicolumn{4}{|l|}{ Overall intelligibility } \\
\hline Median (min-max) & $1(0-3)$ & $0(0-2)$ & $\left(z=-3.64, p<.0001^{* *}\right)$ \\
\hline
\end{tabular}

Also, this finding agrees with a study by AbouElsaad et al. which showed that increased nasalance scores tends to occur in Egyptian-speaking adults [15]. Also, a study on Korean speakers by Seunghee and Seong-Hyeon revealed that adults had significantly higher nasalance scores than children group [20].

As for the effect of etiology, patients who had compensatory errors after repaired velopharyngeal insufficiency by pharyngeal flap represented $45 \%$ of the sample. Also, $17.5 \%$ of the sample was due to VPI not repaired by pharyngeal flap which include four cases had primary palatoplasty for cleft palate

Table 3 The inter rater agreement between the two raters regarding the post therapy parameters of auditory perceptual assessment of speech $(n=32)$

\begin{tabular}{lll}
\hline & Rater 1 vs rater 2 & \\
\cline { 2 - 3 } Degree of nasality & $0.683^{*}\left(<0.001^{*}\right)$ & GOA \\
Glottal & $0.692^{*}\left(<0.001^{*}\right)$ & Good agreement \\
Pharyngealization & $0.472^{*}\left(<0.001^{*}\right)$ & Moderate agreement \\
Consonant imprecision & $0.522^{*}\left(0.001^{*}\right)$ & Moderate agreement \\
Overall intelligibility & $0.531^{*}\left(<0.001^{*}\right)$ & Moderate agreement \\
& & \\
& Value of $K$ & Strength of agreement \\
& $<0.20$ & Poor agreement \\
& $0.21-0.40$ & Fair agreement \\
$0.41-0.60$ & Moderate agreement \\
$0.61-0.80$ & Good agreement \\
$0.81-1.00$ & Very good agreement \\
\hline
\end{tabular}

$k$ KAPPA test, $L O A$ level of agreement, $p p$ value for comparing between rater 1 and 2

*Statistically significant at $p \leq 0.05$ and needed secondary repair. Another two cases with deep pharynx and/or high arched palate, and the size of gap improved after the application of software program. Phua and de Chalain stated that about 20 to $30 \%$ of children with cleft palate will still have VPI resulting in abnormal speech after primary repair [21].

Regarding the auditory perceptual assessment of speech, there was a statistically significant improvement in auditory perceptual assessment after applying the program. Also, there was a positive correlation between the degree of auditory perceptual assessment before therapy and improvement after therapy. So, the higher pre-therapy grades were associated with better improvement after intervention. This finding suggests that a higher degree of auditory perceptual assessment was associated with high patient awareness, good auditory discrimination of correct articulation, and a better chance for correcting these errors. Auditory perceptual assessment is particularly an important criterion in the assessment of speech errors and consequently the effectiveness of speech therapy [22].

The proposed program was effective in decreasing nasometer values. This finding suggests that correcting abnormal articulatory placement decreased the abnormal high nasometer values, which may be explained by changing the abnormal tongue position, thus facilitating the oral direction of sounds. Also, working on discriminating nasal production of vowels and correcting them was effective in decreasing their nasalance scores.

There was a positive correlation between nasometer values for the oral sentence and the degree of open nasality. Also, there was a positive correlation between nasometer values for vowels $/ \mathrm{i} /$ and $/ \mathrm{u} /$. This 
Table 4: Comparison between repaired and unrepaired velopharyngeal insufficiency regarding post-intervention degree of auditory perceptual assessment of speech

\begin{tabular}{|c|c|c|c|}
\hline & $\begin{array}{l}\text { Repaired } \\
\text { VPI } \\
(n=18)\end{array}$ & $\begin{array}{l}\text { Unrepaired } \\
\text { VPI } \\
(n=7)\end{array}$ & $\begin{array}{l}\text { Test of significance } \\
\text { (p) }\end{array}$ \\
\hline \multicolumn{4}{|l|}{ Degree of nasality } \\
\hline $\begin{array}{l}\text { Median (min- } \\
\text { max) }\end{array}$ & $1(0-2)$ & $1(0-2)$ & $(U=61.5, p=.93)$ \\
\hline \multicolumn{4}{|l|}{ Glottal } \\
\hline $\begin{array}{l}\text { Median (min- } \\
\text { max) }\end{array}$ & $0(0-2)$ & $0(0-0)$ & $(U=56, p=.7)$ \\
\hline \multicolumn{4}{|l|}{ Pharyngeal fricative } \\
\hline $\begin{array}{l}\text { Median (min- } \\
\text { max) }\end{array}$ & $0(0-2)$ & $0(0-1)$ & $\begin{array}{l}(U=57.5, p= \\
.745)\end{array}$ \\
\hline \multicolumn{4}{|c|}{ Consonant imprecision } \\
\hline $\begin{array}{l}\text { Median (min- } \\
\text { max) }\end{array}$ & $0(0-1)$ & $1(0-2)$ & $(U=42, p=.22)$ \\
\hline \multicolumn{4}{|l|}{ Overall intelligibility } \\
\hline $\begin{array}{l}\text { Median (min- } \\
\text { max) }\end{array}$ & $0(0-2)$ & $0(0-2)$ & $(U=50, p=.46)$ \\
\hline
\end{tabular}

finding goes with a study by Brunnegård, Lohmander [23], who stated that there was a positive correlation between nasalance scores and hypernasality ratings. This proves that a nasometer is an important part of the initial evaluation of speech in cases of VPD and follow-up. Also, it helps to confirm the rating of hypernasality especially for inadequately trained phoniatrics [23].

The comparison of the post-intervention nasometer values between the group with repaired VPI and the group with unrepaired VPI shows no significant difference between these groups. As mentioned before, the group of unrepaired VPI in this study included was divided into cases with a need for secondary repair and cases improved without need for repair, and this group was small in number so that this study could not prove that speech therapy in repaired VPI is successful more than unrepaired VPI. Further studies are needed to study the actual difference between the two groups.

The program was effective in correcting pharyngeal fricatives completely in $89.5 \%$ of pharyngeal /s/ sound and $76.9 \%$ of pharyngeal / $/$ / sound.

For glottal stops, the program was effective in complete correction of $66.7 \%$ of glottalized / $\mathrm{t} / \mathrm{and} 80 \%$ of glottalized /k/ sound.

Complete correction of lateral fricatives was obtained in $50 \%$ of lateral $/ \mathrm{J} /$.

Yet, complete correction of lateral /s/ could not be obtained; partial correction was only noticed in
Table 5 Comparison between mean of nasometer values before and after the intervention

\begin{tabular}{|c|c|c|c|c|}
\hline Nasometer values & Pre & Post & Test of sig. & $p$ \\
\hline$/ \mathrm{a} /$ & $(n=40)$ & $(n=40)$ & & \\
\hline Min.-max. & $7.0-93.0$ & $3.0-99.0$ & $Z=3.999^{*}$ & $<0.001$ \\
\hline Mean \pm SD & $42.03 \pm 20.0$ & $24.65 \pm 21.03$ & & \\
\hline Median & 44.50 & 22.0 & & \\
\hline /i/ & $(n=40)$ & $(n=40)$ & & \\
\hline Min.-max. & $5.0-96.0$ & $7.0-98.0$ & $t=5.438^{*}$ & $<0.001$ \\
\hline Mean \pm SD & $66.0 \pm 25.78$ & $46.40 \pm 21.96$ & & \\
\hline Median & 76.0 & 45.0 & & \\
\hline$/ \mathrm{u} /$ & $(n=40)$ & $(n=40)$ & & \\
\hline Min.-max. & $6.0-87.0$ & $2.0-98.0$ & $Z=3.636^{*}$ & $<0.001$ \\
\hline Mean \pm SD & $45.23 \pm 25.19$ & $30.35 \pm 23.24$ & & \\
\hline Median & 44.50 & 28.50 & & \\
\hline /b/ & $(n=40)$ & $(n=40)$ & & \\
\hline Min.-max. & $7.0-95.0$ & $0.0-98.0$ & $Z=3.979^{*}$ & $<0.001$ \\
\hline Mean \pm SD & $60.90 \pm 30.27$ & $29.95 \pm 30.36$ & & \\
\hline Median & 75.50 & 16.50 & & \\
\hline$/ \mathrm{t} /$ & $(n=38)$ & $(n=39)$ & & \\
\hline Min.-max. & $10.0-91.0$ & $0.0-92.0$ & $Z=4.112^{*}$ & $<0.001$ \\
\hline Mean \pm SD & $50.18 \pm 28.94$ & $27.05 \pm 27.13$ & & \\
\hline Median & 43.50 & 16.0 & & \\
\hline$/ \mathrm{k}$ & $(n=32)$ & $(n=40)$ & & \\
\hline Min.-max. & $7.0-94.0$ & $0.0-98.0$ & $Z=2.674^{*}$ & $0.007^{*}$ \\
\hline Mean \pm SD & $46.50 \pm 27.15$ & $30.63 \pm 25.17$ & & \\
\hline Median & 41.0 & 20.0 & & \\
\hline Nasal sentence & $(n=40)$ & $(n=40)$ & & \\
\hline Min.-max. & $42.0-92.0$ & $37.0-97.0$ & $t=3.864^{*}$ & $<0.001$ \\
\hline Mean \pm SD & $71.83 \pm 13.01$ & $60.98 \pm 12.15$ & & \\
\hline Median & 71.0 & 60.50 & & \\
\hline Oral sentence & $(n=40)$ & $(n=40)$ & & \\
\hline Min.-max & $8.0-87.0$ & $9.0-99.0$ & $Z=3.623^{*}$ & $<0.001$ \\
\hline Mean \pm SD & $48.78 \pm 19.11$ & $35.25 \pm 18.80$ & & \\
\hline Median & 52.0 & 34.0 & & \\
\hline
\end{tabular}

$t$ paired $t$ test, $Z$ Wilcoxon signed ranks test $p p$ value for comparing between pre and post * Statistically significant at $p \leq 0.05$

${ }^{* *}$ HHighly significant $<.001$

33.3\% of errors. This finding was observed in patients who have retrognathia accompanying VPD which affected correct production of sound $/ \mathrm{s} /$. Lastly, the software program could completely cure $100 \%$ of distorted $/ \mathrm{r} /$ sound and $57.1 \%$ of backing $/ t /$. A study that critically appraised many computer programs for speech therapy and did systematic review stated that level of evidence for CBST was moderate, and it can be complementary to 
Table 6 Correlation between age and nasometer values

\begin{tabular}{lllll}
\hline Nasometer values & & $N$ & \multicolumn{2}{l}{ Age (years) } \\
\cline { 3 - 5 } & & & $\boldsymbol{R}$ & $\boldsymbol{P}$ \\
\hline /a/ & Pre & $\mathbf{4 0}$ & 0.168 & 0.301 \\
& Post & $\mathbf{4 0}$ & 0.238 & 0.140 \\
/i/ & Pre & $\mathbf{4 0}$ & $0.346^{*}$ & $0.029^{*}$ \\
& Post & $\mathbf{4 0}$ & 0.300 & 0.060 \\
/ / / & Pre & $\mathbf{4 0}$ & 0.157 & 0.333 \\
& Post & $\mathbf{4 0}$ & $0.325^{*}$ & $0.041^{*}$ \\
/b/ & Pre & $\mathbf{4 0}$ & 0.249 & 0.121 \\
& Post & $\mathbf{4 0}$ & 0.042 & 0.795 \\
/t/ & Pre & $\mathbf{3 8}$ & 0.105 & 0.530 \\
& Post & $\mathbf{3 9}$ & 0.007 & 0.967 \\
/K/ & Pre & $\mathbf{3 2}$ & $0.420^{*}$ & $0.017^{*}$ \\
& Post & $\mathbf{4 0}$ & 0.177 & 0.275 \\
Nasal sentence & Pre & $\mathbf{4 0}$ & 0.217 & 0.178 \\
& Post & $\mathbf{4 0}$ & 0.052 & 0.750 \\
Oral sentence & Pre & $\mathbf{4 0}$ & $0.326^{*}$ & $0.040^{*}$ \\
& Post & $\mathbf{4 0}$ & $0.397^{*}$ & $0.011^{*}$ \\
\hline
\end{tabular}

$r$ Pearson coefficient

*Statistically significant at $p \leq 0.05$

Table 7 Comparison between repaired and unrepaired velopharyngeal insufficiency regarding post-intervention nasometer values

\begin{tabular}{|c|c|c|c|}
\hline & $\begin{array}{l}\text { Repaired } \\
\text { VPI } \\
(n=18)\end{array}$ & $\begin{array}{l}\text { Unrepaired } \\
\text { VPI } \\
(n=7)\end{array}$ & $\begin{array}{l}\text { Test of significance } \\
\text { (p) }\end{array}$ \\
\hline \multicolumn{4}{|l|}{ /a/ } \\
\hline $\begin{array}{l}\text { Median (min- } \\
\text { max) }\end{array}$ & $20(5-99)$ & $11(5-37)$ & $(U=51, p=.495)$ \\
\hline \multicolumn{4}{|l|}{ /i/ } \\
\hline $\begin{array}{l}\text { Median (min- } \\
\text { max) }\end{array}$ & $\begin{array}{l}42.5(13- \\
98)\end{array}$ & $53(12-72)$ & $(U=56, p=.7)$ \\
\hline \multicolumn{4}{|l|}{ /u/ } \\
\hline $\begin{array}{l}\text { Median (min- } \\
\text { max) }\end{array}$ & $30.5(2-90)$ & $17(3-57)$ & $(U=52, p=.534)$ \\
\hline \multicolumn{4}{|l|}{ /b/ } \\
\hline $\begin{array}{l}\text { Median (min- } \\
\text { max) }\end{array}$ & $16(5-92)$ & $15(4-75)$ & $(U=54, p=.615)$ \\
\hline \multicolumn{4}{|l|}{ /t/ } \\
\hline $\begin{array}{l}\text { Median (min- } \\
\max \text { ) }\end{array}$ & $17(3-92)$ & $23(11-87)$ & $(U=50, p=.82)$ \\
\hline \multicolumn{4}{|l|}{$/ k$} \\
\hline $\begin{array}{l}\text { Median (min- } \\
\text { max) }\end{array}$ & $20(4-98)$ & $26(7-73)$ & $(U=54.5, p=.757)$ \\
\hline \multicolumn{4}{|l|}{ Nasal sentences } \\
\hline $\begin{array}{l}\text { Median (min- } \\
\text { max) }\end{array}$ & $60.5(37-97)$ & $57(52-69)$ & $(U=43, p=.914)$ \\
\hline \multicolumn{4}{|l|}{ Oral sentences } \\
\hline $\begin{array}{l}\text { Median (min- } \\
\text { max) }\end{array}$ & $29(14-88)$ & $32.5(19-55)$ & $(U=50, p=.82)$ \\
\hline
\end{tabular}

Table 8 Correlation between degree of auditory perceptual assessment of speech before intervention and degree of improvement after intervention

\begin{tabular}{lll}
\hline & $r$ & $p$ \\
\hline Degree of nasality & $0.558^{*}$ & $<0.001^{* *}$ \\
Glottalization & $0.683^{*}$ & $<0.001^{* *}$ \\
Pharyngealization & $0.382^{*}$ & $0.015^{*}$ \\
Consonant imprecision & $0.727^{*}$ & $<0.001^{* *}$ \\
Overall intelligibility & $0.728^{*}$ & $<0.001^{* *}$ \\
\hline
\end{tabular}

$r$ Pearson coefficient

*Statistically significant at $p \leq 0.05$

traditional therapy, can increase the frequency of training outside the session, and ease delivery of the service. Also, this study stated that there were factors that assist the success: stimulable phonemes, good auditory discrimination, training for poor auditory discriminated sounds, and auditory and visual feedback [14].

In conclusion, the program was effective in correcting articulatory errors and improving nasality scores, and there is a need for further research about its effects of the other speech sound disorders other than VPD.

Yet, there were some limitations of this study, these included

- Drop out before completing the therapy and poor compliance of some patients.

- Not all the patients had facilities to do home exercises using this program.

\section{Conclusion}

Speech therapy is an important intervention strategy for cases with VPD with speech errors either alone or

Table 9 Correlation between degree of nasality and nasometer values before and after the intervention

\begin{tabular}{|c|c|c|c|c|c|}
\hline \multirow[t]{2}{*}{$\begin{array}{l}\text { Nasometer } \\
\text { values before }\end{array}$} & \multicolumn{2}{|c|}{$\begin{array}{l}\text { Degree of } \\
\text { nasality before }\end{array}$} & \multirow[t]{2}{*}{$\begin{array}{l}\text { Nasometer } \\
\text { values "post" }\end{array}$} & \multicolumn{2}{|c|}{$\begin{array}{l}\text { Degree of nasality } \\
\text { "post" }\end{array}$} \\
\hline & $r_{\mathrm{s}}$ & $p$ & & $r_{\mathrm{s}}$ & $p$ \\
\hline la/ & 0.269 & 0.093 & $/ a /$ & 0.137 & 0.399 \\
\hline /i/ & $0.419^{*}$ & $0.007^{*}$ & /i/ & 0.190 & 0.241 \\
\hline$/ \mathrm{u} /$ & $0.340^{*}$ & $0.032^{*}$ & $/ \mathbf{u} /$ & 0.196 & 0.225 \\
\hline /b/ & 0.233 & 0.148 & $/ b /$ & -0.046 & 0.779 \\
\hline$/ \mathrm{t} /$ & 0.070 & 0.676 & $/ \mathrm{t} /$ & 0.160 & 0.330 \\
\hline$/ \mathrm{k} /$ & 0.231 & 0.203 & $/ \mathrm{k} /$ & $0.316^{*}$ & $0.047^{*}$ \\
\hline Nasal sentence & 0.282 & 0.078 & Nasal sentence & -0.033 & 0.840 \\
\hline Oral sentence & $0.467^{*}$ & $0.002^{*}$ & Oral sentence & $0.317^{*}$ & $0.046^{*}$ \\
\hline
\end{tabular}

$r_{\mathrm{s}}$ Spearman coefficient

*Statistically significant at $p \leq 0.05$ 
with surgery or prosthesis. This study proved that the designed Arabic software program was effective for correcting both speech errors and nasality scores.

\section{Supplementary information}

Supplementary information accompanies this paper at https://doi.org/10. 1186/s43163-020-00036-y.

Additional file 1:. Auditory discrimination window. Awareness window. Production window for syllables

\section{Abbreviations}

VPD: Velopharyngeal dysfunction; VPI: Velopharyngeal insufficiency;

CBST: Computer-Based Speech Therapy

\section{Acknowledgements}

The research team would like to thank the other colleagues in the department. Also, deep thank to the participants in the research and our colleagues.

\section{Authors' contributions}

RM: supervision, established the concept of the research, designed the work, validation and visualization of the results .EE: role in supervision, role in revising the results, writing the original draft, reviewing and editing. AR: role in collecting data, applying the intervention, analyzing the data. RE: designing the software program. All authors read and approved the final manuscript.

\section{Funding}

This research did not receive any specific grant from funding agencies in the public, commercial, or not-for-profit sectors.

\section{Availability of data and materials}

The datasets used and/or analyzed during the current study are available from the corresponding author on reasonable request.

\section{Ethics approval and consent to participate}

The ethics committee of the Faculty of Medicine approved the study (no.0105440). Informed consent to participate in the study was provided by the parent or legal guardian of the cases as they were all children under 16 after explaining the intervention.

\section{Consent for publication}

Not applicable.

\section{Competing interests}

The authors declare that they have no competing interests.

\section{Author details}

'Department, Faculty of Medicine, Alexandria University, Alexandria, Egypt. ${ }^{2}$ Unit of Phoniatrics, Otorhinolaryngology Department, Faculty of Medicine, Alexandria University, Alexandria, Egypt. ${ }^{3}$ Rawag Office, Alexandria, Egypt.

Received: 27 May 2020 Accepted: 27 August 2020

Published online: 04 December 2020

\section{References}

1. Kummer AW (2014). Cleft palate and craniofacial anomalies: effect on speech and resonance, 3rd edition ed. Delmar Cengage, NY. 23-31 p.

2. Dudas JR (2006) Diagnosis and treatment of velopharyngeal insufficiency: clinical utility of speech evaluation and videofluoroscopy. Ann Plastic Surg 56(5):511-517

3. Kirschner RE, Baylis AL (2013) Velopharyngeal dysfunction. In: Neligan PC, Gurtner GC (eds) Plastic surgery: principles and practice, 3rd edn. Elsevier Inc, St. Louis, pp 614-630

4. Shprintzen RJ (2013). The velopharyngeal mechanism. Cleft lip and palate: Springer. p. 741-57.

5. Kummer AW (2014). Cleft palate and craniofacial anomalies: effect on speech and resonance, 3rd ed. Delmar Cengage Learning, NY. 192-5 p.
6. Ruscello D (2007) Treatment of velopharyngeal closure for speech: discussion and implications for management. J Speech Lang Pathol Appl Behav Anal 2(1):55

7. Kotby MN, Abdelhaleem EK, Hegazi M (2015) The velopharyngeal port structure, function and failure. In: Disorders of Speech and Swallowing for Phoniatrics and Communication Disorders. El Harity Print, Cairo, pp 60-64

8. Premkumar S (2011) Clinical application of palatal lift appliance in velopharyngeal incompetence. J Indian Soc Pedodontics Prevent Dentist 29(6):70

9. Alfwaress FS, Bibars AR, Hamasha A, Al Maaitah E (2017) Outcomes of palatal lift prosthesis on dysarthric speech. J Craniofacial Surg 28(1):30-35

10. Kummer AW (2014). Cleft palate and craniofacial anomalies: effect on speech and resonance 3rd ed. Delmar Cengage Learning, NY. 597-602 p.

11. Kummer AW (2008). Cleft palate and craniofacial anomalies: the effects on speech and resonance, 2nd ed. New Albany, NY: Delmar Cengage Learning, New Albany, NY.

12. Kummer AW (2014). Cleft palate and craniofacial anomalies: effect on speech and resonance, 3rd ed. Delmar Cengage Learning, NY. p. 622-38.

13. Dejonckere P, Esch TH Editors (2003). Nasometric assessment of hypernasality in children: optimized speech material and normative values. International Congress Series; Elsevier

14. Furlong L, Erickson S, Morris ME (2017) Computer-based speech therapy for childhood speech sound disorders. J Commun Disord 68:50-69

15. Abou-Elsaad T, Quriba A, Baz H, Elkassaby R (2012) Standardization of nasometry for normal Egyptian Arabic speakers. Folia Phoniatrica et Logopaedica 64(6):271-277

16. Kotby MN, Bassiouny S, El-Zomor M, Mohsen E (1986) Standardization of an articulation test (in Arabic). In: Proceeding of the 9th annual Ain shams medical congress. Egypt, Cairo

17. Abou-Elsaad T, Baz H, Afsah O, Mansy A (2015) The nature of articulation errors in Egyptian Arabic-speaking children with velopharyngeal insufficiency due to cleft palate. Int J Pediatr Otorhinolaryngol 79(9):1527-1532

18. Kotby MN E-SA, Alloush T, Gamal N(1992). 3. Dysarthria Annual Bulletin of Yufuin Kosenenkin Hospital. Hiese. 373-80.

19. Siegel-Sadewitz VL, Shprintzen RJ (1986) Changes in velopharyngeal valving with age. Int J Pediatr Otorhinolaryngol 11(2):171-182

20. Ha S, S-h C (2015) Nasalance scores for normal Korean-speaking adults and children: effects of age, vowel context, and stimulus length. Int J Pediatr Otorhinolaryngol 79(8):1235-1239

21. Phua YS, de Chalain T (2008) Incidence of oronasal fistulae and velopharyngeal insufficiency after cleft palate repair: an audit of 211 children born between 1990 and 2004. Cleft Palate Craniofacial J 45(2):172-178

22. Sell D (2005) Issues in perceptual speech analysis in cleft palate and related disorders: a review. Int J Lang Commun Disord 40(2):103-121

23. Brunnegård K, Lohmander A, van Doorn J (2012) Comparison between perceptual assessments of nasality and nasalance scores. Int J Lang Commun Disord. 47(5):556-566

\section{Publisher's Note}

Springer Nature remains neutral with regard to jurisdictional claims in published maps and institutional affiliations.

\section{Submit your manuscript to a SpringerOpen ${ }^{\circ}$ journal and benefit from:}

- Convenient online submission

- Rigorous peer review

- Open access: articles freely available online

High visibility within the field

- Retaining the copyright to your article

Submit your next manuscript at $\boldsymbol{\nabla}$ springeropen.com 